\title{
Comprehensive Evaluation about Employment Pressure of College Students in Heilongjiang Province Based on the Catastrophe Progression Method
}

\author{
Yingbing $\mathrm{Fan}^{1, \mathrm{a}}$, Yan $\mathrm{Yao}^{1, \mathrm{~b}}$, Lina Sun ${ }^{2, \mathrm{c}}$ \\ ${ }^{1}$ Department of Mathematics, Heihe University, 164300, Heihe City of Heilongjiang, China \\ 2 Department of Chemical Physic, Heihe University, 164300, Heihe City of Heilongjiang, China \\ aemail:fanyingbing0902@163.com, bemail:19616261@qq.com, cemail:44800979@qq.com
}

Keywords: Catastrophe progression, Employment pressure, Questionnaire survey

\begin{abstract}
Employment problem is an important thing that relates Chinese reform, development and stability. University students' employment difficulty has become an indisputable fact that the relationship on employment pressure is imminent. The index data of the various universities' students on the employment pressure in Heilongjiang Province is acquired by questionnaire survey, based on the Catastrophe progression method to establish evaluation system of college students' employment pressure, ratings for college students' employment pressure in Heilongjiang Province College students' employment pressure in Heilongjiang Province has been in serious level.
\end{abstract}

\section{Introduction}

Since China carried out the policy of increased university enrollment, the number of college graduate surged violently. Our country entered the stage of popularization of higher education in a very short period, the biggest characteristic of the current university students' employment is graduates with large amount and high growth, and the characteristic contradicts with the present situation that the whole situation of the employment has not improved obviously. Meanwhile, the situation that the social economy is to admit university students has not shown supply less than demand any longer. Additionally, the preference for region and job as well as to the work too high expectations, aggravate the difficulty of the university students' employment. The difficulty of jobbing has become an indisputable fact that the problem affects not only college students, but also has become the focus of the government at all levels at the same time, and also is the focus of the whole society. Based on the employment pressure bringing the negative effects, the significance that we understand and improve the situation of the college students' employment pressure becomes particularly important. So in terms of above-mentioned questions, we take Heilongjiang Province for granted to carry out the survey of the college students' employment pressure.

\section{The Introduction Of Catastrophe Progression Theory}

Catastrophe Progression Background. Catastrophe theory is put forward by the French mathematician Rene Thom in order to explain hybrid embryos' process of embryology in the late 1960s.The main mathematical origin makes the critical point classified according to potential function, and then studies various discontinuous characteristics near the critical point. This method first decomposes the research object into a number of indicators by different levels, and again put various indexes from low to high to synthesis, use mutations fuzzy membership function to classify a one parameter finally. Namely, the total membership function is calculated, therefore, getting a comprehensive evaluation method that analyze and sort the evaluation target. Catastrophe progression method does not use weights to index, but weigh the relative importance of each evaluation index, with the quantitative and qualitative analysis, so as to reduce the subjectivity of general fuzzy algorithm with the scientific and rationality. And the method is simple and accurate, wide range of applications. Currently, seven elementary mutation model of common use in catastrophe theory are shown as follows: 
Fold catastrophe

Cusp catastrophe

Swallowtail catastrophe $f(x)=x^{3}+u x$

$f(x)=x^{4}+u x^{2}+v x$

$$
f(x)=x^{5}+u x^{3}+v x^{2}+w x
$$

The formulas $f(x)$ shows a potential function with a state variable of a system; $f(x, y)$ shows a potential function with two state variables that are $\mathrm{x}$ and $\mathrm{y}$; Coefficient of state variables $u, v, t, w$ show the control variables of state variables. The unified formula of cusp catastrophe, the unified formula of Swallowtail catastrophe and the unified formula of Butterfly catastrophe are as follows:

$$
\left\{\begin{array}{l}
x_{u}=\sqrt{u} \\
x_{v}=\sqrt[3]{v}
\end{array}, \quad\left\{\begin{array} { l } 
{ x _ { a } = \sqrt { a } } \\
{ x _ { b } = \sqrt [ 3 ] { b } , } \\
{ x _ { c } = \sqrt [ 4 ] { c } }
\end{array} \quad \left\{\begin{array}{l}
x_{a}=\sqrt{a} \\
x_{b}=\sqrt[3]{b} \\
x_{c}=\sqrt[4]{c} \\
x_{d}=\sqrt[5]{d}
\end{array} .\right.\right.\right.
$$

Some Notes of Catastrophe Progression Evaluation Method. (1) Evaluation decision principle. Multi-objective catastrophe evaluation decision has three principles: one is the "non-complementary "evaluation decision, its schematic symbol is connected with a solid line. The second is "complementary" evaluation decision. "Non-complementary" principle refers to some irreplaceable between control variables of a system, namely "choosing the small from the big". "Complementary" evaluation decision principle refers that some variables can compensate each other in a system, so that the corresponding -value achieve higher average, in other word, which takes the average of these control variables' corresponding. The third is a principle of "complementary" after the threshold, whose schematic symbol use a dotted line and a solid line to connect with labeling threshold value around these lines. In practical problems, there are plenty of situations that are the complementary between targets until targets reach a certain threshold with the choice of depending on reality.(2)Valuing problem of catastrophe progression. We assign for each indicator and normalize index value. In a unified formula, Control variables show the state variables' characteristic of the different aspects, whose original data's range and the unit of measure may not be the same. So, before using unified formulas, we must transform the original data of the control variable into 0-1 within the scope of the dimensionless standardized value. For the basic method of standardization that the index is higher and more safety and the index is lower and more safety respectively is Eq1.

$$
b_{i}=\frac{a_{i}-a_{\min }}{a_{\max }-a_{\min }} \quad b_{i}=\frac{a_{\text {max }}-a_{i}}{a_{\max }-a_{\min }}
$$

$a_{i}$ is the original value of each index, $b_{i}$ is the standardization of each index.

\section{The Analysis of University Students' Employment Pressure in Heilongjiang Province}

Employment pressure refers to psychological tension phenomenon that the college students meet interaction between many different variables and personal factors in employment situation. As well, someone describes employment pressure as "external threat that college students meet employment situation surpass the psychological and physiological reaction by its ability".

Establish College Students' Employment Pressure Evaluation System. According to the ideas of the catastrophe progression method, we decompose the factors that affect the university students' employment pressure step by step and establish the system of pressure level evaluation index with the importance degree of index as norm to sequence, and decide the catastrophe model by the number of all levels. Employment pressure is mainly manifested in two aspects of external factors and internal factors according to the existing research achievements of college students' employment pressure. Choosing six representative indexes construct the index evaluation system of college students' employment pressure, as is shown in Figure 1. This is a three-level index system, 
index of each class is sequenced according to the importance, important indicator lies in head, and secondary indicators rank behind. Secondary index system, the external factor is swallowtail catastrophe system, as a non-complementary model; Internal factor is swallowtail catastrophe system, as a complementary model; the first level index system is cusp catastrophe system, as complementary model.

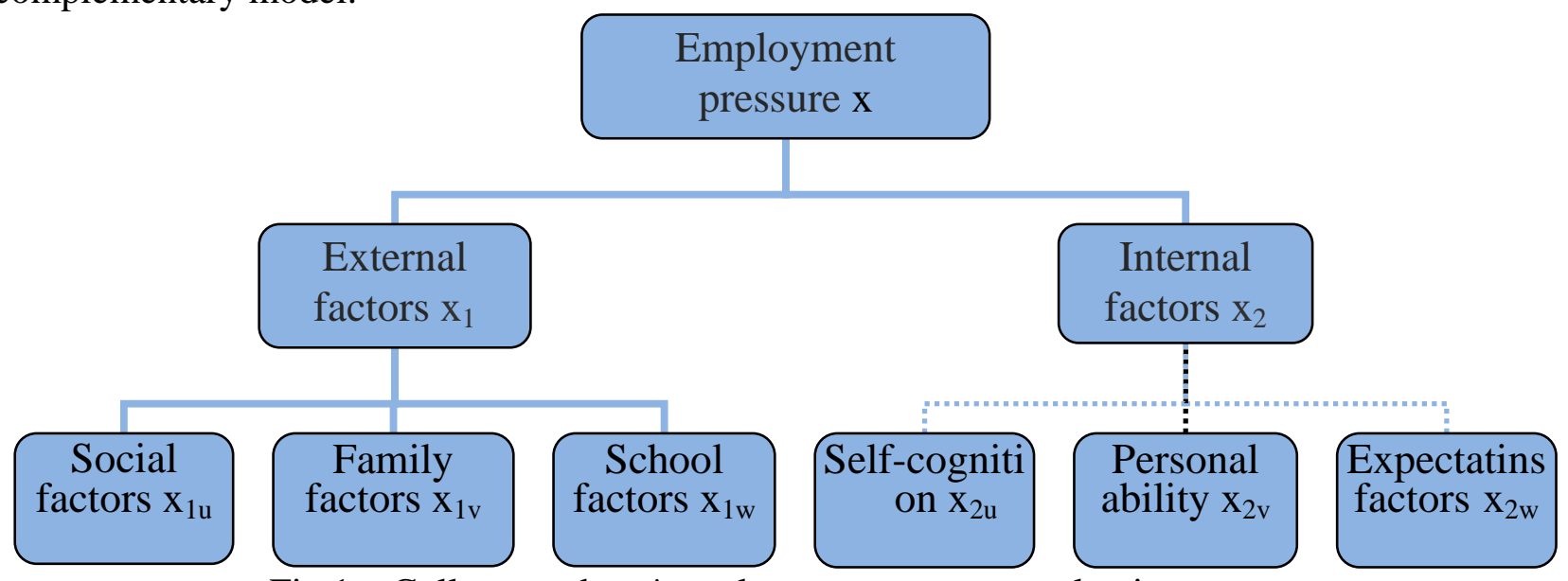

Fig.1 College students' employment pressure evaluation system

Source of employment stress include external factors and internal factors.

The Source of the External Factors. (1) Social factors. With the rapid development of economic globalization, economic development has become the social mainstream's task; people's material life level is also boom. Profession is distinguished with different levels gradually, and then the values of university students' employment appear corresponding changes with the change of the society naturally. The condition with so-called good jobs for fewer men but large number of people must bring the system of intense competition. This kind of situation will bring psychological pressure for the university students' employment. In terms of the social factors, questionnaire sets up five questions. (2) Family factors. "Family background" have been our country tradition since ancient times. Children in the process of growth will inevitably be influenced by these factors, and the value of most people is gradually set up as early as childhood, so the employment duty from this hat of family makes children strive for it, but when this kind of sense of responsibility is achieved, anxiety will be generate. In view of the family factors, questionnaire also set up four questions. (3) School factors. With the popularization of higher education in our country, enrollment expansion cause the number of college students to increases year by year so that the competition of university students' employment tend to be violent. However, when the employer selects college students, the employer processes these courses based on the social status of the school, comprehensive strength ranks, etc. And these schools have high social reputation and influence and students' employment has a comparative advantage, which leads to college students who are out of these schools tend to be in disadvantageous situation of a position competition because of the limit of school resources and professional Settings, and so on, which leads to employment pressure. In view of the school factors, questionnaire also set up six questions.

The Source of the Internal Factors. (1) Self-cognitive factors. College students' self-awareness is not clear, do not know their own advantages, not clear their own goals, don't understand their own interests, the self-awareness of the inaccurate will become the bottleneck of college students when they face to choose jobs. In view of self-cognitive factors, questionnaire also set up five questions.(2)The factors of personal ability. Levels of these abilities will generate employment pressure to the graduates. At the same time how to correctly face to be selected, how to correctly recognize yourself, find their own advantage, foster strengths and circumvent weaknesses also become important factors that college students whether ease the employment pressure or not. In terms of the factors of personal ability, the questionnaire also set up six questions.(3) The factors of expectations. College students can't really touch society on campus, which leads to lack for the cognition of jobs for them, too high or too low expectations will affect the employment of college 
students. When they are going to end their lives of college and face choices, they can't correctly choose to suit their own career; it will be related to the pressure in employment. In terms of the factors of expectations, questionnaire set up four questions.

The Collection or Data and Standardization. Make integrated questionnaires according to the system of evaluation index, and will refine index and factor. Each index sets multiple problems, and obtains to survey the source of employment pressure from multiple perspectives. This questionnaire has 30 questions and questionnaire survey is conducted to various college students in Heilongjiang province, and to collect back the data to input, clean outliers and incompatible data, screening of repeated cases and normal distribution test data, etc. 5000 valid questionnaires are sort out finally. We normalize the original data according to the requirements of the corresponding index value and index assignment requirements, as is shown in Table 1.

Table 1 Original values of various indicators and standardized values

\begin{tabular}{ccccc}
\hline index & original value & maximum & minimum & standardized value \\
\hline Social factors & 3.7 & 6 & 1 & 0.460 \\
Family factors & 2.9 & 5 & 1 & 0.525 \\
School factors & 2.8 & 5 & 1 & 0.550 \\
Self-cognitive factors & 2.1 & 6 & 1 & 0.220 \\
The factors of personal ability & 2.8 & 4 & 1 & 0.600 \\
The factors of expectations & 2.5 & 4 & 1 & 0.500 \\
\hline
\end{tabular}

The University Students' Employment Pressure Ratings In Heilongjiang Province. Three indicators of social factors, family factors and school factors" make up a system of non-complementary swallowtail catastrophe, there are

$$
x_{1 u}=\sqrt{0.460}=0.678, x_{1 v}=\sqrt[3]{0.525}=0.807, x_{1 w}=\sqrt[4]{0.550}=0.861 .
$$

According to the principle of "choosing the small from the big”, the indicators are external factors:

$$
x_{1}=\min \left\{x_{1 u}, x_{1 v}, x_{1 w}\right\}=0.678 .
$$

Similarly, Three indicators of "self-cognitive factors, the factors of personal ability and factors of expectations "make up a system of non-complementary swallowtail catastrophe, there are

$$
x_{2 u}=\sqrt{0.220}=0.469, x_{2 v}=\sqrt[3]{0.600}=0.843, x_{2 w}=\sqrt[4]{0.500}=0.841 .
$$

According to the principle of "complementary" evaluation decision,

$$
x_{2}=\text { average }\left\{x_{2 u}, x_{2 v}, x_{2 w}\right\}=\frac{0.469+0.843+0.841}{3}=0.718 .
$$

External factors and internal factors constitute complementary cusp catastrophe, so indicators for university students' employment pressure in Heilongjiang Province are

$$
x=\text { average }\left\{x_{1}, x_{2}\right\}=\frac{0.678+0.718}{2}=0.698 \text {. }
$$

According to the level test of university students' employment pressure, the university students' employment pressure level is divided into five levels, as is shown in Table 2.

Table 2 College students' employment pressure rating

\begin{tabular}{cccccc}
\hline rating & mild & moderate & More serious & serious & Super serious \\
\hline employment pressure & $0-0.20$ & $0.21-0.40$ & $0.41-0.6$ & $0.61-0.80$ & $0.81-1$ \\
\hline
\end{tabular}

According to the calculated results, as can be seen that college students' employment pressure in Heilongjiang Province belongs to the level of serious danger, which is about to enter the super serious door. 


\section{Conclusions}

Plenty of people have no plans for one's prospective career. Although most students have a part-time job or internship experience, most internship experiences are not conforming to their own majors. Many people with generally external image don't realize inner tall good integrity will be more valuable than outer beauty, who are desperate, giving up studies, finally they feel there is no chance of winning jobs for them, psychological pressure rise abruptly. Students in ordinary colleges for don't hold agreed attitude to social recognition of colleges' majors. Our country helps college students solve the relative policies of the employment problem that is paid less attention to because of the low salary, which causes difficulty of employment and the pressure rises sharply.

College students first adjust good state of mind in a new era. They must identify the status of Chinese economic development and employment situation, update their concepts of employment at once, and seek truth from facts to analyze self to determine appropriate employment expectations. In the process of searching for jobs, they should pay attention to the adjustment of state of mind, don't be arrogant after success, don't be discouraged after setback. The key is to pay attention to the cultivation of their ability and the all-round improvement of literacy, practically shape you in accordance with the need of society, so that the college students are excellent enough in the brutal competition of the society.

\section{Acknowledgements}

College students' innovation and entrepreneurship training plan in Heilongjiang Province (201413744039), Heihe University teaching reform project (Xjg1429, Xjg1437)

\section{References}

[1] Y.Q.Song, T. Zhang, Y. Lin and J. Liang. Chinese health education.Vol.3(2014),03:p.241-245. (In Chinese)

[2] Y.B. Fan. Empirical analysis based on catastrophe theory Vietnamese financial crisis. (MS., Ningxia University, China 2010).

[3] Y.B.Fan:International Conference on Applied Sciences,Engineering and Technology (Qingdao, China, July 28-29,2014). Vol.8, p.1541.

[4] Y.B. Fan: Science Technology and Engineering, Vol. 10 (2010) 2, p. 380. (In Chinese) 